\title{
Biological substantiation of improvement of biotechnological map of production of aquaculture products "eco-direction"
}

\author{
O. V. Honcharova ${ }^{1}$, R. P. Paranjak ${ }^{2}$, O. P. Rudenko ${ }^{2 *}$, N. A. Lytvyn ${ }^{2}$ \\ ${ }^{1}$ Kherson State Agrarian University, Kherson, Ukraine \\ ${ }^{2}$ Stepan Gzhytskyi National University of Veterinari Medicine and Biotechnology, Lviv, Ukraine
}

E-mail: OlgaRudenko86@ukr.net;anelsatori@gmail.com

Received: 14.02.2020 Accepted 10.03.2020

\begin{abstract}
The influence of the forage factor on the rate of development of tilapia during cultivation in recirculating aquaculture systems has been investigated. Positive results were obtained regarding the feeding of natural feeds after pre-treatment of the basic medium for cultivation. A model installation of tilapia cultivation with advanced technology of feeding functionally active components is offered, which maximally brings aquaculture production to organic. The efficiency of tilapia cultivation in the polyculture of Oreochromis mosambicus and Florida Red was evaluated. The results of the morphometric evaluation of hydrobionts with a comparative analysis of the effectiveness of the use of Arthrospira (Spirulina) platensis, Artemia salina and amaranth flour in the general diet of tilapia are presented.
\end{abstract}

Keywords: Hydrobionts; Morpho-metric analysis; Hydrochemical regime; Feeding of natural feeds; Processing of the basic environment; Ecologically safe production of aquaculture

\section{Introduction}

European integration tendencies for attracting the experience of developed countries contribute to the development of domestic aquaculture, the establishment of technologically - developed production base in the industry and are the basis for increasing the volume of cultivation and fishing of commercial fish to meet the needs of consumers with quality aquaculture products. The need for rational use of bioresources with the involvement of the latest biotechnologies in our country is one of the prerequisites for improving technological aspects of hydrobiotic cultivation. Such improvement aims at increasing the yield of a useful product of the technological process on the one hand and maximally preserving the nutritional characteristics of aquaculture products on the other (Goncharova, 2016; Grytsynyak, 2018). These tasks, as well as the requirements of ecological safety of aquaculture products, increase the urgency of improving the technological aspects of the entire aquaculture production complex, starting with the preparation of quality and safe feeds. In the context of environmental degradation, the role of natural adaptogens, biologically active substances, contributes to providing the body with hydrobionts with all the necessary nutrients.

The development of aquaculture is based on the use of production and resource potential, which needs to be restored as a result of changes in hydro-ecosystems (Paranyak, 2014). It is known that, along with classical methods of aquaculture on the basis of reservoirs of natural and artificial origin, recently a trend oriented towards the cultivation of aquatic organisms in recirculating aquaculture systems (PAC) (Sharilo, 2016). This allows you to obtain products under the most controlled conditions, which eliminates the effects of contamination of its harmful and dangerous to health and the environment substances (Vergolyas, 2016). However, this type of aquaculture has at least two disadvantages: the relatively high cost of production and that it is obtained in conditions that are significantly different from natural, while the popularity among consumers is ecologically safe products, as close as possible to the characteristics of organic. Therefore, in practice, it is effective to combine the two areas of aquaculture production, for example, fish grown in the RAS can be used to fish reservoirs, where there is an increase in weight to marketable. In order to approximate the production of PAC by characteristics to organic, it is necessary to consider the possibility of improving the technological map through the use of specially processed natural feeds, introduction to the general diet in the composition of relevant biologically active additives. The introduction of such technology into the aquaculture production process will allow to influence and adjust the rate of ontogeny of aquatic organisms and fish productivity.

\section{Literature Review}

\section{Data analysis and problem statement}

In the professional literature the results of researches testifying to efficiency of use of additives of various formulations in aquaculture are quite widely presented (Goncharova, 2016; Grytsynyak, 2013; Zolotaryova, 2008). The authors note in the studies the importance of meeting the energy needs of fish. In particular, the technology of easily digestible feed additives with high nutritional value has been developed for carp (Grytsynyak, 2013; Grytsynyak, 2018). The results of scientific and practical studies on the use in the biotechnological map of growing fish of phytopreparations allow to conclude that this method of feeding is characterized by soft action, low toxicity and high content of biologically active substances (Spolaore, 2006). 
Methods of cultivation of phytoplankton and zooplankton for feeding young fish are considered in (Zolotaryova, 2008). Numerous studies have been devoted to the optimization of the feed ration of fish production under RAS conditions (Sharilo, 2016). Many authors have considered the directions of greening production, in particular, O. Dudar (Dudar, 2014) considered the dynamics of the internal market of certified organic products. The following literature sources show positive results from studies of the effects of unconventional feed in aquaculture (Grytsynyak, 2014; Grytsynyak, 2018). However, the issue of complex improvement of the technological process of cultivation of tilapia in RAS conditions by pre-treatment of the components of the diet and conditions of keeping and feeding, has not been sufficiently studied.

\section{Aim and objectives of the study}

The aim of the research was to investigate the effect of forage factor on morphometric, physiological and productivity parameters for the cultivation of tileapia Oreochromis mosambicus and Florida Red in ROS. In accordance with the goal, the following tasks were set: to experimentally and practically prove the feasibility of using the proposed method of feeding tilapia; to study the rate of development of tilapia in ontogeny against the background of the influence of the forage factor during cultivation in ROS; to investigate the physiological state of the body of tilapia against the background of feeding. Materials and methods of experimental research. The practical part of the research was carried out on the basis of the Scientific-Experimental Student Center "Aquatic bioresources and aquaculture of Dnieper" of Dnipro State Agrarian and Economic University and the Department of Ecology of the Stepan Gzhytskyi National University of Veterinary Medicine and Biotechnologies Lviv.

The biotechnological map of hydrobiotic cultivation envisaged the use of complete diets based on biologically active and natural components excluding growth promoters, antibiotics, etc. Aquaculture products obtained under such restrictions were labeled on the packaging with the label "organic biology" (agriculture biologique) and, due to their quality characteristics, had a competitive advantage in the market since it was sold at twice the price.

The study of the peculiarities of forming a qualitative diet for hydrobionts when fed with natural components was carried out on the basis of Institut national de la recherche agronomique (INRA, National Institute for Agricultural Research, France). Based on the Scientific-Experimental Center "Aquatic Bioresources and Aquaculture of Prydniprov'ya, Ukraine), basic researches were carried out on the influence of certain factors (fodder, hydrochemical, hydrobiological, physiological and biochemical) on the functional status of the tilapia organism (Zheltov, 2003).

During the implementation of ichthyological, hydrobiological, hydrochemical studies, they were guided by conventional methods and fishery standards (Zheltov, 2003; Plohinsky, 1969). The results obtained were recorded in a working journal, followed by statistical analysis.

After feeding the tilapia with natural feed, the water lost its transparency for 10-15 minutes. They fed tilapia repeatedly during the day at the rate of $3-5 \%$ of body weight, depending on the water temperature. Hydrochemical assessment and monitoring of the tilapia ethology were systematically carried out. Depending on the hydrochemical state, water was replaced by up to $50 \%$. The temperature of the aquariums during the experimental period was within the normal range (27.5-28.50C). In the experimental part of the study of the rate of development of tilapia used aquariums of 250 liters. During the experiment to study the influence of the feed factor of natural origin on the Mughro-metric parameters of tilapia, the cultivation of the natural feed in the reservoir was carried out, using the Zaruka medium and sea salt (depending on the natural feed base). Subsequent treatment with a special method in a bioreactor with a change in the structure of water as a reference medium (Pivovarov, 2007).

Cultures of cyanobacteria Arthrospira (Spirulina) platensis and crustaceans Artemia salina were cultured in the laboratory. The scientific and practical part of the research consisted of the preliminary stage (preparatory), the main stage and the stage of studying the effectiveness of the implementation of the proposed method of improving the biotechnological map of the cultivation of hydrobionts on an industrial scale on a large scale. During the preparation of the preparatory stage, a series of studies were conducted on the selection of model objects for the experiment, setting the optimal concentrations for the base environment. The proposed method of treatment of the basic environment, cultivation of phytoplankton and zooplankton for use in the scheme of feeding of hydrobionts, is presented in more detail in the works (Pivovarov, 2017; Goncharova, 2018; Mikolenko, 2017). The body weight of the tilapia was determined by reference weighing on electronic scales.

Study group 1 received the supplement according to the scheme: LHG (common diet) + amaranth flour. Experimental group 2: GGR + concentrate Arthrospira (Spirulina) platensis + Artemia salina. When forming the feed mixture, all ingredients were introduced gradually manually. The group where the fish consumed only OGG was the control group. The method of improving the cultivation of hydrobionts in ROS is reflected in the declarative patents of the authors (Kobets, 2017; Kobets, 2016).

\section{Results}

Comparative characterization of Florida Red and Oreochromis mosambicus as model objects of industrial cultivation. One of the main environmental factors influencing the development of living organisms is the feed of artificial and natural origin. Weighing results for each species of hydrobionts showed that Florida Red had more active growth rates. The average body weight of pink tilapia was $45.5 \mathrm{~g}$, while the same in Mozambique was equal to $24.2 \mathrm{~g}$ (Figure 1). It should be noted that for the second species typical are lower rates of growth rate in the natural environment.

The average values of total length in Florida Red specimens were $14.1 \mathrm{~cm}$, while Oréochromis mosambicus was $11.1 \mathrm{~cm}$. With regard to the study of the short length and height of the body of Florida Red, we note that the parameters averaged over the group of $11.4 \mathrm{~cm}$ and $4.2 \mathrm{~cm}$, while the 0 . mossambicus obtained the following results: $8.9 \mathrm{~cm}$ and $3.3 \mathrm{~cm}$, respectively.

In addition to the results obtained, it can be noted that visual observation of the tilapia etiology during the experimental part showed that fish of both species did not show significant aggression to specimens (representatives) of the other species. However, for each species without exception, the developmental and age characteristic is the aggressive ethology of the male and female tilapia during the period of sexual formation and spawning period.

Investigation of the metabolic processes of hydrobionts against the background of the influence of the forage factor. The study of the nutrition of freshwater fish species has been the subject of ongoing research aimed at fisheries development. Adaptation of the organism of aquatic organisms to factors of industrial and technological character remains at the same time, while maintaining the high quality characteristics of aquaculture products. Feeding young tilapia took into account that there is no natural feed base in the PAC system. Therefore, it is important to meet the body's need for hydrobionts in protein, micro- and macro-elements, amino acids, vitamins during active growth periods. When interpreting the results of the study of the hydrochemical state take into account that increasing the amount of dissolved carbon dioxide "acidifies" the aqueous medium; increases the alkalinity, which contributes to 
changing the activity parameters of hydrogen ions. According to the results of the studies, all parameters of the hydrochemical state of the tanks were within acceptable limits of fluctuation (Table 1).

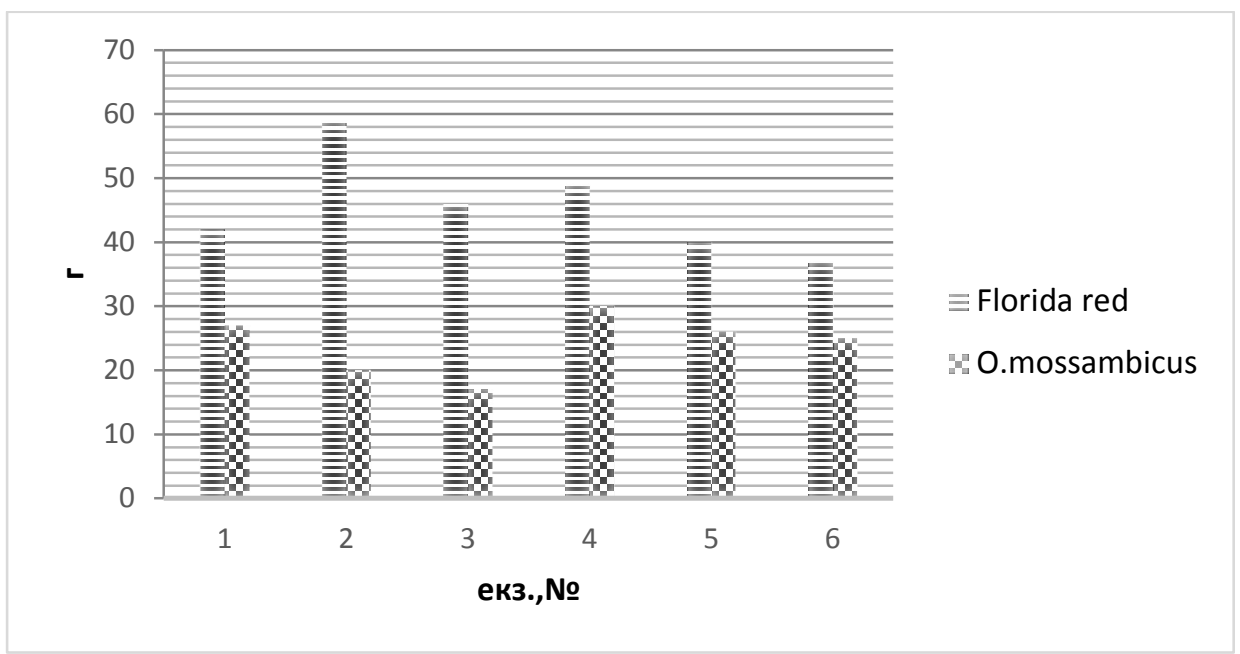

Figure 1. Analysis of the rate of development by tilapia body mass index.

The morphometric analysis of the following indicators presented in Figure 2 showed that Florida Red had higher growth rates than Oreochromis mossambicus.
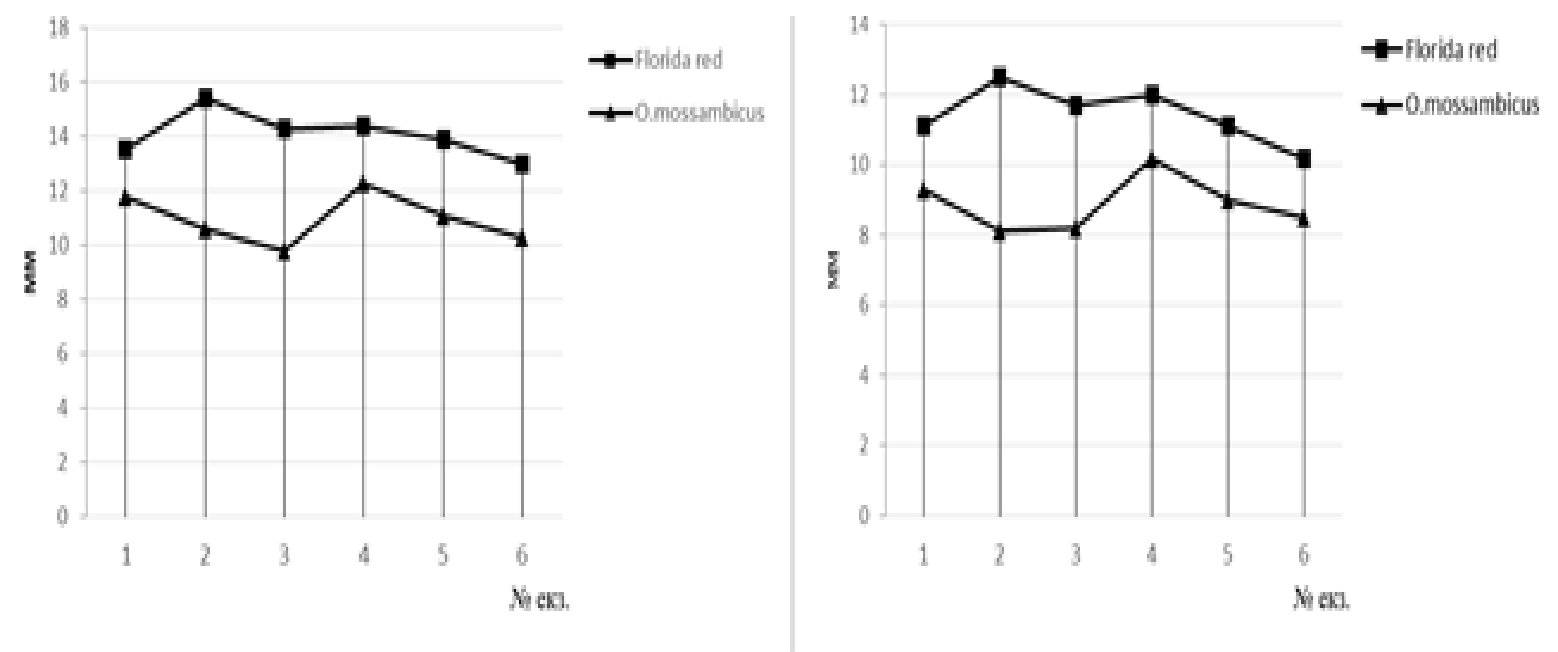

Figure 2. The results of the Mophro-metric analysis of tilapia in polyculture: $a, b$ - measurement of body length of small (a) and large (b).

Table 1. Analysis of the hydrochemical state of tilapia cultivation tanks.

\begin{tabular}{|c|c|c|}
\hline Name of indicator & $\begin{array}{l}\text { Mean of } \\
\text { indicator }\end{array}$ & MAC* \\
\hline Water temperature, ${ }^{\circ} \mathrm{C}$ & $28,6 \pm 0,3$ & $25-30$ \\
\hline Hydrogen index & $7,1 \pm 0,1$ & $6,5-7,5$ \\
\hline Oxygen concentration, $\mathrm{mg} / \mathrm{l}$ & $3,9 \pm 0,1$ & Not less 3,5 \\
\hline Ammonium $\mathrm{NH}_{4+}, \mathrm{mg} / \mathrm{l}$ & $0,12 \pm 0,31$ & Not more 10 \\
\hline Nitrates $\mathrm{NO}_{3-,} \mathrm{mg} / \mathrm{l}$ & $15,13 \pm 2,41$ & Up to 100 \\
\hline Nitrites $\mathrm{NO}_{2-}, \mathrm{mg} / \mathrm{l}$ & $0,31 \pm 0,04$ & Up to 1 \\
\hline Oxidation, mg O/l & 13,5 & Up to 16,8 \\
\hline
\end{tabular}

* MAC is the maximum allowable concentration.

The functional state of the tilapia organism depends on the concentration of nitrites, given that the conditions of fish production are PAC, this is of paramount importance. The study of nitrite concentration showed that the processes of biogenic nitrogen (nitrification) processing were within the physiological and hydrochemical norm in fisheries. The results of the experiment showed that cyanobacteria and zooplankton in the tilapia, which was treated daily with ZGR, had higher rates of growth, digestion (experimental group 2) than in the group where amaranth flour was introduced into experimental group (experimental group 1). Thus, the yield of cultivation in the experimental group 2 was $96.2 \%$, in the experimental group 1 - 94.6\%, in the control group, this indicator was $92.3 \%$. 
The results of morphometric evaluation of tilapia against the use of an additional forage factor made it possible to note the positive effect and stimulating effect on metabolism in the body of hydrobionts, which contributed to the acceleration of development and weight gain in the experimental groups. Thus, the average body weight of the 30-day tilapia in experimental group 1 was $19 \%$ higher than the value in control, while the difference between experimental group 2 and control group was $24.6 \%$.

Fish that consumed Arthrospira (Spirulina) platensis and Artemia salina (Experiment 2) feed for 60 days had higher rates of development in all experimental groups: the parameter exceeded the control values by $15.2 \%$, while tilapia in in experimental group 1 had a lower mean body weight than in control $8.4 \%$ and $6.25 \%$ less than in experimental group 2 .

The morphometric evaluation of tilapia and the comparative analysis of the experimental groups prior to the control made it possible to note the positive influence of the natural forage factor in feeding the tilapia. However, in experimental group 2 the parameters were higher than in the first experimental group and control (Table 2).

Table 2. Influence of forage factor on morphometric parameters of tilapia, $M \pm m, n=6$.

\begin{tabular}{|c|c|c|c|}
\hline \multirow[b]{2}{*}{ Indexes (I) } & \multicolumn{3}{|c|}{ Groups of experimental research } \\
\hline & Control & $\begin{array}{l}\text { Research } \\
1\end{array}$ & $\begin{array}{l}\text { Research } \\
2\end{array}$ \\
\hline Icompactness, $\%$ & $64,9 \pm 0,9$ & $65,2 \pm 0,6$ & $65,9 \pm 0,7$ \\
\hline Ibigotry, $\%$ & $22,6 \pm 1,2$ & $24,9 \pm 0,9$ & $25,6 \pm 0,9$ \\
\hline $\begin{array}{l}\text { Ibody height, } \\
(\%)\end{array}$ & $30,8 \pm 1,0$ & $32,1 \pm 0,9$ & $32,9 \pm 0,6$ \\
\hline Igreed & $3,2 \pm 0,9$ & $2,9 \pm 0,8$ & $3,3 \pm 0,5$ \\
\hline
\end{tabular}

A study of the exterior profile of tilapia by leading body indexes showed that in Experiment group 2 the parameters exceeded the physiological norm values in control and experimental group 1 . In addition, the Fulton fatigue ratio in experimental group 2 exceeded the control group and the first group. When studying the influence of a forage factor on the metabolic processes in fish, the study of blood composition is informative (Table 3).

Table 3. The results of the study of the influence of feed factor on the morpho-functional indicators of blood tilapia 60 days of age, $\mathrm{M} \pm \mathrm{m}, \mathrm{n}=6$.

\begin{tabular}{|c|c|c|c|}
\hline \multirow[t]{2}{*}{ Parameters } & \multicolumn{3}{|c|}{ Groups of experimental research } \\
\hline & Control & $\begin{array}{l}\text { Research } \\
1\end{array}$ & $\begin{array}{l}\text { Research } \\
2\end{array}$ \\
\hline The number of red blood cells, $\mathrm{B} / \mathrm{I}$ & $1,4 \pm 0,6$ & $1,5 \pm 0,6$ & $1,5 \pm 0,6$ \\
\hline Hemoglobin content, $\mathrm{g} / \mathrm{l}$ & $\begin{array}{ll}66,1 & \pm \\
1,3 & \end{array}$ & $68,7 \pm 1,2$ & $71,0 \pm 1,2$ \\
\hline Hematocrit, (\%) & $\begin{array}{l}44,8 \\
0,9\end{array}$ & $46,6 \pm 0,8$ & $47,1 \pm 0,7$ \\
\hline
\end{tabular}

The obtained results provide an opportunity to note the stimulating effect of metabolic processes in the body of tilapia of two experimental groups. The total number of erythrocytes, indicating better erythropoiesis in the blood of tilapia, which additionally received natural feed was higher relative to the control group. Which, in turn, correlated with the hemoglobin concentration in the blood of the fish. It is likely that the proposed method of feeding natural feeds contributed to the activation of the course of physiological and biochemical processes in the body of tilapia, which in turn reflected in better rates of growth rate.

\section{Discussion}

The qualitative characteristics of already finished aquaculture products depend on the general diet, feeding conditions and the system of keeping the aquatic organisms. Therefore, in fish cultivation, all technological processes must be as controlled as possible from the beginning of fish cultivation to the receipt of finished aquaculture products to the consumer table (Goncharova, 2016; Goncharova, 2018). This paper presents the results of improving the biotechnological map of obtaining aquaculture products "ecodirection". Feeding tilapia with natural feed had a positive effect on the rate of development: the mean body weight of the 30-day tilapia in experimental group 1 was $19 \%$ higher than the control value, while the difference between experimental group 2 and fish in the control group was $24.6 \%$. Tilapia with Arthrospira (Spirulina) platensis and Artemia salina (Experiment group 2 ) was added to the HRC for 60 days for all experimental groups: the parameter exceeded the control values by $15.2 \%$, while tilapia in in experimental group 1 had a lower mean body weight than in control $8.4 \%$ and $6.25 \%$ less than in experimental group 2 . It should be noted that the research of Yu.I. Grytsynyak (Grytsynyak, 2004) on the effect of natural feed, non-traditional components on the carp organism during industrial cultivation showed positive results in the productive and biological effect of nontraditional feeds (grain bards, sprouted wheat grains, etc.).

Therefore, current ideas about obtaining organic aquaculture products foresee the exclusion from the technological map of the use of growth promoters of hormonal origin, antibiotics and the like. Therefore, the topic of this work is not only scientific, but also practical value. Pre-treatment of uterine solution of cultivation of microalgae contributes to a positive change in the functional characteristics and chemical composition (amino acid composition) of Arthrospira (Spirulina) platensis, Artemia salina (Pivovarov, 2017). Experience in the use of phytoplankton, in particular, microalgae in fisheries is reflected in the scientific work of Merzlova GV (2014). The author notes the positive effect of Chlorella, Scenedesmus, Spirulina, as they are a natural feed of many species of fish and, after entering the body, have a corrective effect on metabolic processes (Merzlova, 2014). As an alternative way of increasing the protein nutrition of hydrobionts, in particular breeding heifers of the Lubinsk flake carp Grytsynyak II, Tuchapskaya A. Ya. (2013) propose to use drugs that have a high content (up to 50\%) of readily available protein (Grytsynyak, 2004; Grytsynyak, 2013). At the same time, the research by Krazhan et al. reflect the positive results of using high protein protein feed of Daphnia magna Straus on compound feed and hydrolysis yeast when feeding fish (Krazhan, 1979). 
The results of the application of tilapia for feeding Arthrospira (Spirulina) platensis, Artemia salina and amaranth flour presented in this paper provide an opportunity to draw conclusions regarding the activation of the physiological and biochemical mechanisms of the regulatory system that corrects the growth rate and overall development of the tilapia organism. Thus, the output of young tilapia in experimental group 2 was $96.2 \%$, in experimental group $1-94.6 \%$, while in the control group this parameter was $92.3 \%$. A study of the external profile of tilapia by leading body indexes showed that in Experiment Group 2, the compactness and ductility indices were $65.9 \%$ and 3.3 , respectively; body fatness and height indices were $25.6 \%$ and $32.9 \%$, respectively. The parameters were higher than in the other groups of the experiment. The next External Profile metric - Fulton's fatigue ratio in Study Group 2 exceeded values in Study Group 1 and Control.

Zolotaryova O.K. defines biotechnology as a series of technologies that involve the use of biological processes of living organisms in industry, agriculture and other fields of application. Recently, biotechnologies have been developing using photo-autotrophs, in particular microalgae (Zolotaryova, 2008). Therefore, the technology of uterine solution for cultivation of algae and the method of feeding young tilapia proposed in this article contributes to the improvement of the overall functional status of the tilapia organism at the expense of natural feed without the use of hormonal origin growth promoters. It is likely that the improvement of development, the better output of youth is due to the activation of the metabolic processes of the body of experimental tilapia. The hemoglobin content in the blood of tilapia of experimental group 2 was higher than the parameters of other experimental groups and equaled $71.0 \mathrm{~g} / \mathrm{l}$, as well as the number of erythrocytes, which was equal to $1.5 \mathrm{~T} / \mathrm{l}$. Note that in the study of the influence of feed factor (natural feed, herbal remedies, probiotics, etc.) on the body of hydrobionts, one of the informative indicators is hematological parameters. Tushnitskaya N.Y. (2018) presented information on the improvement of erythropoiesis and protein metabolism in fish when using biologically active drugs (Goncharova, 2018).

The results of the study of the mafro - metric indices of tilapia in the polyculture of Florida Red and Oreochromis mosambicus gave reason to note that the body weight of Florida Red was higher than Oreochromis mosambicus and was $45.5 \mathrm{~g}$, while the same indicator in Mozambican was equal to $24.2 \mathrm{~g}$. The overall length in Florida Red was $14.1 \mathrm{~cm}$, while in Oréochromis mosambicus the figure was $11.1 \mathrm{~cm}$. Regarding the study of the length and height of the body of Florida Red we note that the indicators averaged in the group of $11.4 \mathrm{~cm}$ and $4.2 \mathrm{~cm}$, while the 0 . mossambicus obtained the following results: $8.9 \mathrm{~cm}$ and $3.3 \mathrm{~cm}$, respectively.

\section{Conclusion}

When growing tilapia in Florida Red and 0 . mossambicus polyculture, intensive development is characteristic of Florida Red. Studies have confirmed the ethological compatibility of Florida Red and 0 . mossambicus cultivation in polyculture. The results of the experiment provided an opportunity to analyze the influence of the forage factor on the main indicators of tilapia growth and development. In particular, fish that received cyanobacteria and zooplankton (experimental group 2) daily had higher rates of growth and feed uptake than in the group fed amaranth meal (experimental group 1) when fed to ZGR. Feeding tilapia for 30 days with the addition of Arthrospira (Spirulina) platensis and Artemia salina contributed to a $24.6 \%$ increase in the rate of development in fish compared to the control group. While the mean body weight of the 30 -day tilapia in Experiment Group 1 exceeded $19 \%$ of the control value.

The use of spirulina and zooplankton for 60 days in ZGR promoted the activation of metabolic processes, which had a positive effect on the weight gain and average body weight. Thus, tilapia youth in the second experimental group had a higher rate of development of hydrobionts in relation to all groups of the experiment: the parameter exceeded the value in the control group by $15.2 \%$ and the indicator in the first experimental group by $6.25 \%$. While tilapia in experimental group 1 had a lower average body weight than in the control by $8.4 \%$. The yield from cultivation in Experiment Group 2 was better than in all experimental groups and was $96.2 \%$, in Experiment Group 1-94.6\%, in the control group it was the lowest and was $92.3 \%$.

The study of the exterior profile of tilapia by leading indexes of the body structure showed that in the experimental group 2 parameters exceeded within the physiological norm values in the control and experimental group 1. The results obtained showed a positive effect of feeding in the first and second experimental groups relative to the control groups groups. The functional status of the tilapia organism, which received pre-treated cyanobacteria and zooplankton daily in the diet, was better, as evidenced by blood counts (total erythrocyte count and hemoglobin concentration). Hydrochemical parameters corresponded to the normative values in aquaculture when growing hydrobionts in RAS.

\section{References}

Pivovarov A. (2017). Biotesting of plasma-chemically activated water with the use of hydrobionts // A. Pivovarov, S. Mykolenko, O. Honcharova // Eastern-European Journal of Enterprise Technologies, 10 (88). - P. 44 - 50. DOI: 10.15587/1729-4061.2017.107201 Spolaore P. (2006). Joannis-Cassan C, Duran E, Isambert A. Commercial applications of microalgae. Journal of bioscience and bioengineering. 101(2): 87-96.

Vergolyas, M.R. (2016). Toxic effects of heavy metals on the hydrobionts' organism [Text] / M. R. Vergolyas, V. V. Goncharuk // Journal of Education, Health and Sport, 6, 6. - P. 436-444.

Goncharova, O. V. (2016). Harmonization and biotechnological updating of methods of determining the quality of biological products [Text] / O.B. Goncharov, AM Pugach // Young Scientist, 9 (36): 111-114.

Goncharova, O. V, Astre, P., Astre M. (2016). Prospects for the development of aquaculture in Ukraine in the light of European experience / OV Goncharov, P. Astre., M. Astre // Scientific journal "Borysten". 04 (297) 24-26.

Goncharova, O. V, Tushnitskaya, N. Y. (2018). Physiological substantiation of the use of non-traditional method of processing raw materials in aquaculture / OV Goncharov, N.Y. Tushnytska // Fisheries Science of Ukraine. 1. - C. 54 - 64.

Grytsynyak. (2004). II The use of wheat bards in feeding carp / II. Hrytsynyak // Scientific. Herald of the Lviv National. Acad. wind. medicine them. S.S. Lviv, 6 (No. 3): 46 - 51.

Grytsynyak. (2013). II Influence of ecological conditions and intensification measures on the growth of breeding yearlings of the Lubian scaly carp / II Grytsynyak, A. Ya, No 3. 46-54.

Grytsynyak. (2018). II Some results of recent research by the Institute of Fisheries / II. Grytsynyak, OM Tretyak // Proceedings of the 1st International Scientific and Practical Conference "Modern Problems of Rational Use of Aquatic Bioresources", Kyiv, May 1517, 2018: Kiev: About format. 8 - 12.

Dudar, O. T. (2014). Organic agro-production in Ukraine: trends of development and ways of strengthening the position of producers / OT Dudar // Bulletin of Sumy National Agrarian University. Series: Economics and Management. Vip. 4. P. 73-77. 
Zheltov, Yu.O. (2003). Methodical instructions for conducting experiments on feeding fish/Yu.O. Zheltov // Fisheries. Vip. 62. P. 2328.

Zolotaryova, O. K. (2008). Prospects for the use of microalgae in biotechnology / Ok. Zolotaryova, EI Shnyukova // Kiev: Alterpress. p. 234.

Krazhan, S. A. (1979). Daphnia magna Straus cultivation experience on compound feed and hydrolysis yeast / SA Krazhan, AF Antipchuk, TG Litvinova // Fisheries. No. 29. - p. 58 - 61.

Merzlova, G. V. (2014). The content of chlorophyll in the biomass of spirulina during the action of different doses of trace elements in the nutrient medium / GV Merzlov // Animal biology. 16, No. 2. - P. 71-76.

Method for determining acute lethal (KND 211.1.4.055-97) and chronic (KND 311.1.4.056-97) water toxicity of Ceriodaphnia affinis Lilljebord [Text]. - Kiev, - 17 p.

Mikolenko, S.Yu., Goncharova, O. V., Pugach, A. M. (2017). Innovative methods of processing raw materials. Dnipro: Zhurfond, 224p.

Paranyak, R. P. (2014). Some aspects of environmental risk of anthropogenic contamination of small Rivers in Lviv Region / RP Paranyak, TP Ostash // Scientific Bulletin of Lviv National University of Veterinary Medicine and Biotechnology. Hedgehog. T. 16, No. 2 (3). - P. 318-326. - Access mode: http://nbuv.gov.ua/UJRN/

Plohinsky, N. A. (1969). Guide to biometrics for Zootechnics / NA. Plokhinsky // M .: Kolos, p. 256.

Kobets AS, Goncharova OV, Pugach AM Patent holders Kobets, A. S., Goncharova, O. V., Pugach, A. M. (2017). Device for recirculating water supply for organic production in aquaculture pat. 120645 Ukraine. № in 201705357; claimed 05/31/2017: Publications 10/11/2017, Issue \# 21 - Publications

Kobets, A. S., Goncharova, O. V., Pugach, A. M., Kobets, A. S., Goncharova, O. V., Pugach. A. M. (2016). A method of improving the productivity and quality of pond fish production Pat. 111576 Ukraine. № in 201606064.

Sharilo, Y. u., Vdovenko, N. M., Fedorenko, M. O., Gerasymchuk, V. V., Heaven, G.I. (2016). Modern aquaculture: from theory to practice. Practical Guide, 119 p.

\section{Citation:}

Honcharova, O.V., Paranjak, R.P., Rudenko, O.P., Lytvyn, N.A. (2020). Biological substantiation of improvement of biotechnological map of production of aquaculture products "eco - direction". Ukrainian Journal of Ecology, 10(1), 261-266.

\begin{tabular}{|l|l}
$(\mathrm{cc}) \mathrm{EY}$ \\
$\mathrm{Br}$
\end{tabular} 